\title{
Assessing criminal justice involvement as an indicator of human immunodeficiency virus risk among women in methadone treatment
}

\author{
Matthew W. Epperson, (Ph.D., M.S.W. ${ }^{\mathrm{a}, *}$, Maria R. Khan, (Ph.D.) ${ }^{\mathrm{b}}$, \\ Daniel P. Miller, (Ph.D. $)^{\mathrm{c}}$, Brian E. Perron, (Ph.D. $)^{\mathrm{d}}$, \\ Nabila El-Bassel, (D.S.W. $)^{\mathrm{e}}$, Louisa Gilbert, (Ph.D.) ${ }^{\mathrm{e}}$ \\ ${ }^{a}$ Center for Behavioral Health Services and Criminal Justice Research, Rutgers University, New Brunswick, NJ 08901, USA \\ ${ }^{\mathrm{b}}$ School of Public Health, University of Maryland, College Park, MD 20742, USA \\ ${ }^{\mathrm{c}}$ School of Social Work, Boston University, Boston, MA, USA 02215 \\ ${ }^{\mathrm{d}}$ School of Social Work, University of Michigan, Ann Arbor, MI 48109, USA \\ ${ }^{\mathrm{e}}$ Social Intervention Group, Columbia University School of Social Work, New York, NY 10027, USA
}

Received 1 October 2009; received in revised form 26 February 2010; accepted 2 March 2010

\begin{abstract}
This study examines the relationship between criminal justice involvement and high-risk sexual partnerships among a random sample of 416 women in methadone treatment in New York City. Logistic regression models were used to estimate the associations between recent criminal justice involvement (arrest or incarceration in the past 6 months) and recent high-risk partnerships (multiple sex partners, sex trading, or sex with a risky partner in the past 6 months) when adjusting for sociodemographic factors and recent regular drug use. Women with recent criminal justice involvement demonstrated higher odds of engaging in high-risk sex partnerships. Although regular drug use was a significant confounder of several of these relationships, recent arrest or incarceration remained significantly associated with multiple sex partnerships, sex with a risky partner, and engaging in unprotected sex and a high-risk partnership even after controlling for regular drug use and other social stressors. This study highlights the vulnerability of drug-involved women offenders to human immunodeficiency virus (HIV) risk and points to the need for investigation into the role of arrest and incarceration as factors that may contribute to HIV infection. (C) 2010 Elsevier Inc. All rights reserved.
\end{abstract}

Keywords: Criminal justice involvement; HIV risk; Methadone treatment

\section{Introduction}

Addressing the burden of human immunodeficiency virus (HIV) faced by women in the criminal justice system is an important public health task. Women offenders display rates of HIV that are three to five times that of the general population of women (Belenko, Langley, Crimmins, \& Chaple, 2004; Maruschak, 2005). For over 15 years, the prevalence of HIV among incarcerated women has been even higher than among incarcerated men. In U.S. prisons

* Corresponding author. Center for Behavioral Health Services and Criminal Justice Research, Rutgers University, 176 Ryders Lane, New Brunswick, NJ, USA 08901. Tel.: +1 201234 9357; fax: +1 7329321233.

E-mail address: mwepperson@gmail.com (M.W. Epperson). and jails, the highest rates of HIV are found among African American (3.0\%) and Hispanic (2.9\%) women (Maruschak, 2004) — rates that are considerably greater than the estimated HIV prevalence among African American $(0.06 \%)$ and Hispanic $(0.02 \%)$ women in the general U.S. population (CDC, 2008). For some female offender populations, the levels are staggering; studies in the New York City area document HIV rates of $18 \%$ among sampled female jail inmates and $17 \%$ of sampled women on probation or parole (Belenko et al., 2004; NYCDOH, 1999). Women are also the fastest-growing segment of the U.S. criminal justice population, and 1 in 89 women are currently under some form of correctional control (Frost, Greene, \& Pranis, 2006; Pew, 2009). Despite these trends, there has been limited research on drivers of HIV risk among women offenders, and 
few HIV prevention interventions have been designed specifically to target the complex needs of justice-involved women (El-Bassel, Ivanoff, Schilling, Borne, \& Gilbert, 1997; Mullings, Marquart, Carr, \& Hartley, 2004; StatonTindall et al., 2007). Research that examines factors that influence HIV risk among women offenders to inform HIV prevention interventions is clearly warranted.

The underlying causes for disproportionate HIV levels among women in the criminal justice system are not entirely clear. There appears to be a strong link between criminal justice involvement and HIV-related sexual risk behaviors for women; past studies have found that women with incarceration histories are significantly more likely than nonincarcerated women to exchange sex for money or drugs, to have multiple and concurrent sexual partnerships, and to have been the victim of forced sex (Hammett, Harmon, \& Rhodes, 2002; Khan, Miller et al., 2008; Khan, Wohl et al., 2008; Kim et al., 2002). Some have argued that criminal justice involvement itself may contribute to HIV risk by exacerbating the instability of social networks, economic vulnerability, and stigma, thus increasing the likelihood of HIV and other health risk behaviors (Blankenship, Smoyer, Bray, \& Mattocks, 2005; Browning, Miller, \& Lisa, 2001; Wheelock \& Uggen, 2005). In addition, arrest or incarceration is a disruptive life event that destabilizes intimate partnerships, which are protective against sexual risk behaviors such as multiple and concurrent partnerships (Browning et al., 2001; Comfort, Grinstead, McCartney, Bourgois, \& Knight, 2005; Rindfuss \& Stephen, 1990). During an incarceration, the prisoner's partner may seek additional sexual partners to fill emotional or financial needs (Browning et al., 2001). Absence of a partner, with freedom from restrictions on sexual behavior, may lead released inmates to new and multiple sexual partnerships (MacGowan et al., 2003).

One of the most common explanations for the link between criminal justice involvement and HIV risk and prevalence among women is the role of drug use (Altice et al., 2005; El-Bassel et al., 1995; Epperson et al., 2009; Grella, Annon, \& Anglin, 2000). Over the past two decades, changes in sentencing laws related to illicit drug use have spurred a dramatic increase of drug-involved women in the U.S. criminal justice system (Mauer \& Kins, 2007). Most women offenders are arrested for lower level charges including drug violations and offenses associated with substance abuse, such as shoplifting and prostitution (Greenfeld \& Snell, 2000). Nearly half of women confined in local jails report committing their last offense under the influence of alcohol or drugs (Karberg \& James, 2005). Concurrently, growing evidence suggests that substance abuse is perceived by women as increasing sexual drive and is likely to impair judgment and negotiation skills resulting in an increased risk for having unwanted sex, sex with multiple concurrent partners, and not using protection during sex (Castillo Mezzich et al., 1997; El-Bassel et al., 1998; Sterk, 1999, 2002). Given the high degree of overlap between drug use and criminal justice involvement among women, it is difficult to disentangle each factor's potential role in contributing to HIV risk.

In addition to drug use, women in the criminal justice system face many social hardships and psychological distress, factors that may drive the association between criminal justice involvement and HIV. HIV risk factors that are overrepresented among women offenders include mental illness (Blank \& Eisenberg, 2007; Greenfeld \& Snell, 2000), histories of physical and sexual victimization (Belenko, Lin, O'Connor, Sung, \& Lynch, 2005; Harlow, 1999), and homelessness (Greenfeld \& Snell, 2000; Somlai, Kelly, Wagstaff, \& Whitson, 1998). Women of color are particularly susceptible, facing increased risk for both criminal justice involvement and HIV infection (Blankenship et al., 2005). Because women in the criminal justice system experience high vulnerability to these stressors, any study on HIV risk among women offenders should carefully address the potential confounding effect of these factors. Such studies are difficult to conduct because there are limited data sources that include good measurement of HIV risk, criminal justice involvement, as well as social stressors, drug use, and psychological distress.

The purpose of this study is to examine the associations between criminal justice involvement and high-risk sexual partnerships among women in drug treatment in New York City while controlling for background factors that may confound the association between criminal justice involvement and HIV risk. We use data from baseline interviews of a prospective study whose primary aim was to assess social and psychological determinants of HIV infection among women enrolled in methadone maintenance treatment programs. By studying a sample of women with similar drug dependence histories, for whom we also have thorough measures on recent drug use, social hardship, and psychological distress, this article serves to examine the relationship between criminal justice involvement and sexual HIV risk for drug-involved women while controlling for an array of potential confounding factors. This study responds to a pressing need to understand factors that drive high levels of HIV among women offenders and thus will improve our understanding of how to best plan effective HIV prevention interventions for this vulnerable and understudied population.

\section{Materials and methods}

\subsection{Participants and procedures}

Data for this study come from a larger epidemiologic study designed to examine determinants of HIV risk among drug-involved women. A methadone-maintained sample was chosen for several reasons, including this group's relative stability compared with other drug-using populations as well as its continued vulnerability to drug use, sexual risk behaviors, and criminal involvement (Gilbert, El-Bassel, 
Rajah, Foleno, \& Frye, 2001; Marsch, 1998; Mays, Gordon, Kelly, \& Forman, 2005). Using a random number generator in SPSS, 750 women were randomly selected from a total population of approximately 1,700 women enrolled in 14 methadone maintenance treatment programs in New York City. About three fourths $(n=559)$ agreed to participate in a screening interview. Of these 559 women, 427 met eligibility criteria, which included (a) being female between the ages of 18 and 55 years, (b) being enrolled in methadone treatment for at least 3 months, and (c) during the past year, having had a sexual relationship with someone described as a boyfriend, girlfriend, spouse, regular sexual partner, or father of her children. Approximately $97 \%$ of women who were eligible $(n=416)$ participated in a 90-minute structured interview for this study.

Data were collected between 1998 and 2000 by female research assistants with at least a bachelor's degree who completed a 5-day training that included human subjects issues, interviewing techniques, modeling, and role-playing interview practice. To improve accuracy of self-reported sexual behaviors, we used the timeline follow-back method, which incorporates the use of a calendar, recallenhancing techniques, and visual cues to facilitate the recall of sexual behaviors (Copersino, Meade, Bigelow, \& Brooner, 2010). Participants gave informed consent to participate in the study and were compensated $\$ 5$ for the screening interview and $\$ 25$ for participating in the baseline interview. The institutional review boards of Columbia University and the participating methadone treatment programs approved the study protocol. A detailed study description has been detailed in previous work (El-Bassel, Gilbert, Wu, Go, \& Hill, 2005; Wu, ElBassel, Gilbert, \& Morse, 2006).

\subsection{Measurement}

\subsubsection{Outcomes: High-risk sexual partnerships}

We measured dichotomous indicators of HIV riskrelated sexual partnerships in the past 6 months, including (a) multiple (two or more) sexual partnerships; (b) sex trading, defined as exchanging sex for drugs or money; (c) sex with a risky partner, defined as a partner with known or suspected HIV infection or who was a recent injection drug user; and (d) unprotected sex, defined as having at least one unprotected vaginal or anal sex act. To further specify the level of HIV risk involved in unprotected sex, we constructed the outcome of high-risk partnership and unprotected sex, defined as having both unprotected sex and at least one of the following (all in the past 6 months): multiple sex partnerships, sex trading, and/or sex with a risky partner.

\subsubsection{Exposure: recent criminal justice involvement}

Was defined as having been arrested (apprehended by the police and charged with a crime) or incarcerated (spent one or more nights in custody) in the past 6 months.

\subsubsection{Sociodemographics}

Self-reported sociodemographic data included participant age, race/ethnicity, monthly income, marital status, years of education, employment history, length of time in methadone treatment, and history of homelessness. Participants also self-reported their HIV infection status and whether they had been diagnosed with a sexually transmitted infection (STI) in the past 6 months. The Childhood Sexual Abuse Interview was used to ascertain whether the participant had a history of childhood sexual victimization (Sgroi, 1982).

\subsubsection{Drug use}

Lifetime and past 6-month use of illicit drugs was assessed using the Drug Use and Risk Behavior Questionnaire (El-Bassel, Gilbert, Schilling, \& Wada, 2000). This instrument asks whether the participant had ever used a specific drug and, if so, how often they used it in the past 6 months. For the purpose of this study, six drug use groupings were defined: (a) heroin, (b) stimulants (including amphetamine, methamphetamine, and powder cocaine), (c) crack (or freebased) cocaine, (d) marijuana, (e) prescription drugs used without a prescription (including analgesics, tranquilizers, and sedatives), and (f) injection drug use of any kind. Regular use was defined for each of the six drug groupings as using the drug once a week or more frequently in the past 6 months.

\subsubsection{Psychological distress}

Psychological distress was measured using the Brief Symptom Inventory (BSI; Derogatis, 1993), which assesses severity of 53 psychological distress symptoms over the prior 7 days $(\alpha=.96)$. We used the global severity index of the BSI, which is calculated by averaging all completed responses, with a possible range of $0-5$ (higher scores indicating higher levels of psychological distress).

\subsection{Data analysis}

Descriptive frequencies and/or means were calculated for sociodemographic and behavioral variables. Past 6-month regular drug use and HIV risk variables were assessed and stratified by whether the participant had been arrested or incarcerated in the past 6 months. Differences in regular drug use and HIV risk variables between those with and without recent arrest or incarceration were tested using chi-square tests of independence.

Logistic regression was used to estimate unadjusted and adjusted odds ratios (ORs) and 95\% confidence intervals (CIs) for associations between past 6-month criminal justice involvement and each past 6-month high-risk sex partnership. Adjusted analyses were conducted in two phases. In the first adjusted model, we controlled for the following sociodemographic variables: race/ethnicity, age, education, income, marital status, recent homelessness, recent unemployment, time in methadone treatment, current infection with HIV or another STI, history of sexual abuse, 
psychological distress (as measured by the BSI global severity index), and whether the participant had any samesex partnerships in the past 6 months. Because we expected drug use to exert the greatest confounding effects, we estimated a second adjusted model that controlled for the previous sociodemographic variables plus past 6-month regular use of each of the following: heroin, stimulants, crack cocaine, marijuana, prescription drugs used without a prescription, and any injection drug.

\section{Results}

\subsection{Sample characteristics}

\subsubsection{Sociodemographics}

The mean age among women was nearly 40 years (Table 1). Approximately half (48\%) identified as Hispanic/ Latina, 31\% African American, 17\% White, and the remaining $4 \%$ were of Asian or other racial/ethnic backgrounds. The average educational attainment was approximately 11 years. Women reported low average monthly income (\$845) and employment in the past 6 months (21\%), and greater than half of the sample had ever been homeless $(53 \%)$. Sex with a female partner in the past 6 months was somewhat rare $(n=37,9 \%)$, and of these women, more than half $(n=25)$ also reported having sex with male partners. More than $90 \%$ of the sample $(n=375)$ reported ever being tested for HIV, and 312 of these women (83\%) reported

Table 1

Characteristics of the study sample: women aged 22 to 55 years enrolled in methadone maintenance treatment programs, New York City $(N=416)$

\begin{tabular}{lc}
\hline Age, $M(S D)$ & $39.8(6.7)$ \\
Race/Ethnicity & $199(48 \%)$ \\
Hispanic/Latina & $128(31 \%)$ \\
Black/African American & $70(17 \%)$ \\
White & $19(4 \%)$ \\
Asian/Other & $11.0(2.5)$ \\
Education (years), $M(S D)$ & $845(798)$ \\
Monthly income (dollars), $M(S D)$ & $82(20 \%)$ \\
Currently married & $88(21 \%)$ \\
Employed in the past 6 months & $76(18 \%)$ \\
Self-reported HIV infection & $50(12 \%)$ \\
Self-reported STI infection: past 6 months & $9.2(7.2)$ \\
Years on methadone, $M(S D)$ & $0.84(0.71)$ \\
BSI-Global severity index, $M(S D)$ & $230(55 \%)$ \\
History of sexual abuse & $220(53 \%)$ \\
History of homelessness & \\
Lifetime drug use history & $413(99 \%)$ \\
Heroin & $370(89 \%)$ \\
Stimulants (including amphetamine and powder cocaine) & $283(68 \%)$ \\
Crack or freebased cocaine & $362(87 \%)$ \\
Marijuana & $246(59 \%)$ \\
Drugs without a prescription & \\
(including analgesics, tranquilizers, and sedatives) & $276(66 \%)$ \\
Injected any type of drug & \\
Criminal justice involvement & $294(71 \%)$ \\
Ever arrested or incarcerated & $46(11 \%)$ \\
Arrested or incarcerated: past 6 months &
\end{tabular}

being tested for HIV two or more times in their lifetime. Approximately $18 \%$ of the sample $(n=76)$ reported known HIV infection status.

\subsubsection{Sexual abuse history and psychological distress}

Greater than half of the women in this sample reported a history of sexual abuse (55\%). The average score on the BSI global severity index was 0.84 (range $=0-3.7, S D=0.71$ ). This value is comparable to those found among other druginvolved female populations (El-Bassel et al., 1997), but it is substantially higher than the estimated average of 0.37 for the general female population (Derogatis, 1993).

\subsubsection{Lifetime drug use history}

Nearly all of the women in this study ( $n=413,99 \%)$ reported heroin use in their lifetime; the three women who did not report lifetime heroin use reported lifetime use of other opiates. Other commonly used substances were stimulants (89\% lifetime use), marijuana $(87 \%)$, and crack or freebased cocaine $(68 \%)$. About two thirds $(66 \%)$ of the sample reported an injection drug use history, and 59\% had used prescription drugs without a prescription.

\subsubsection{Criminal justice involvement}

Incarceration and arrest history were commonly reported (Table 1). Seventy-one percent reported either being arrested or incarcerated in their lifetime, and $11 \%(n=46)$ had been arrested or incarcerated in the past 6 months. For those women incarcerated in the past 6 months, the average length of incarceration was approximately 4 days.

\subsection{Past 6-month regular drug use by past 6-month arrest or incarceration}

Women who had been arrested or incarcerated in the past 6 months demonstrated significantly higher levels of several types of regular drug use, including crack cocaine (35\% vs. $11 \% ; p<.001)$, marijuana $(24 \%$ vs. $8 \% ; p<.001)$, drugs used without a prescription $(20 \%$ vs. $6 \% ; p<.001)$, and injecting any type of drug (22\% vs. $11 \% ; p<.05)$. Past 6 month regular heroin or stimulant use did not differ significantly between women who had or had not been recently arrested or incarcerated (Table 2).

\subsection{Past 6-month HIV risk indicators by past 6-month arrest or incarceration}

Women who had been recently arrested or incarcerated reported higher levels of three high-risk sex partnerships compared to women with no recent criminal justice involvement, including multiple sex partners $(30.5 \%$ vs. $11 \% ; p<.001)$, sex trading ( $28 \%$ vs. $9 \% ; p<.001)$, and having a risky sex partner $(52 \%$ vs. $27 \% ; p<.001)$. Proportions of women having unprotected sex were comparable between women with (54\%) and without $(53 \%)$ recent criminal justice involvement. Self-reported 
Table 2

Past 6-month regular drug use and HIV risk indicators by arrest or incarceration in the past 6 months among women aged 22 to 55 years enrolled in methadone maintenance treatment programs, New York City $(N=416)$

\begin{tabular}{|c|c|c|c|c|c|c|c|}
\hline \multirow[b]{2}{*}{ Indicators } & \multicolumn{2}{|c|}{$\begin{array}{l}\text { Total sample } \\
(N=416)\end{array}$} & \multicolumn{2}{|c|}{$\begin{array}{l}\text { Participant was } \\
\text { not arrested or } \\
\text { incarcerated in } \\
\text { past } 6 \text { months } \\
(n=370)\end{array}$} & \multicolumn{2}{|c|}{$\begin{array}{l}\text { Participant was } \\
\text { arrested or } \\
\text { incarcerated in } \\
\text { past } 6 \text { months } \\
(n=46)\end{array}$} & \multirow[b]{2}{*}{$\chi^{2}(d f=1)$} \\
\hline & $n$ & $\%$ & $n$ & $\%$ & $n$ & $\%$ & \\
\hline \multicolumn{8}{|l|}{ Past 6-month regular drug use ${ }^{a}$} \\
\hline Heroin & 82 & 20 & 70 & 19 & 12 & 26 & 1.33 \\
\hline Stimulants (including amphetamine and powder cocaine & 26 & 6 & 23 & 6 & 3 & 6 & .01 \\
\hline Crack cocaine & 55 & 13 & 39 & 11 & 16 & 35 & $20.96 * * *$ \\
\hline Marijuana & 41 & 10 & 30 & 8 & 11 & 24 & $11.50 * * *$ \\
\hline $\begin{array}{l}\text { Drugs without a prescription (including analgesics, } \\
\text { tranquilizers, sedatives) }\end{array}$ & 30 & 7 & 21 & 6 & 9 & 20 & $11.80 * * *$ \\
\hline Injected any type of drug & 52 & 12.5 & 42 & 11 & 10 & 22 & $4.04 *$ \\
\hline \multicolumn{8}{|l|}{ Past 6-month high-risk partnerships } \\
\hline Two or more sex partners & 54 & 13 & 40 & 11 & 14 & 30.5 & $13.95 * * *$ \\
\hline Sex trading & 47 & 11 & 34 & 9 & 13 & 28 & $14.85 * * *$ \\
\hline Risky sex partner & 125 & 30 & 101 & 27 & 24 & 52 & $12.05 * * *$ \\
\hline Any unprotected sex & 221 & 53 & 196 & 53 & 25 & 54 & .03 \\
\hline \multicolumn{8}{|l|}{ HIV/STI status } \\
\hline Self-reported STI in past 6 months & 50 & 12 & 41 & 11 & 9 & 20 & 2.78 \\
\hline Self-reported HIV infection & 76 & 18 & 62 & 17 & 14 & 30.5 & $5.13 *$ \\
\hline
\end{tabular}

${ }^{a}$ Regular drug use is defined as use of each drug at least once per week in the past 6 months.

$* p<.05$.

$* * * p<.001$.

HIV infection was more prevalent among women recently arrested or incarcerated $(30.5 \%)$ than among women with no recent arrest or incarceration $(17 \% ; p<.05)$.

\subsection{Recent criminal justice involvement and high-risk sexual partnerships}

\subsubsection{Multiple sex partnerships}

Women who were arrested or incarcerated in the past 6 months had more than three times the odds of having two or more sex partnerships in the past 6 months as women without recent criminal justice involvement (unadjusted $\mathrm{OR}=3.61,95 \% \mathrm{CI}=1.78-7.33$ ). Adjusting for sociodemographic and other background characteristics changed the estimate minimally. After additional adjustment for regular drug use, the estimate weakened slightly but remained significant (adjusted OR $[\mathrm{AOR}]=3.02,95 \%$ $\mathrm{CI}=1.23-7.43$ ). Regular crack use, which was associated with criminal justice involvement, was also strongly associated with multiple partnerships (AOR $=4.25,95 \%$ CI $=1.89-9.58$; Table 3).

\subsubsection{Sex trading}

Recent criminal justice involvement was strongly associated with exchanging sex for money or drugs in the past 6 months (unadjusted $\mathrm{OR}=3.89,95 \% \mathrm{CI}=$ 1.87-8.10). After adjustment for respondent sociodemographic and other background factors, the OR was reduced to $3.02(95 \% \mathrm{CI}=1.28-7.13)$. The decreased estimate was primarily due to adjustment for recent homelessness and psychological distress. Each of these variables was associated with recent criminal justice involvement, and the multivariable analysis indicated that recent homelessness and psychological distress were strongly associated with sex trade in the past 6 months (homelessness: $\mathrm{AOR}=2.71,95 \% \mathrm{CI}=1.09-6.72$; BSI $/$ GSI score: $\mathrm{AOR}=2.58,95 \% \mathrm{CI}=1.69-3.96)$. When further adjusting for regular drug use, an association remained, but the estimate was no longer statistically significant $(\mathrm{AOR}=2.25,95 \% \mathrm{CI}=0.86-5.88)$. Drug use confounded the association between criminal justice involvement and sex trading; women who were regular crack users were more likely to have engaged in sex trading in the past 6 months versus nonregular users of crack $(\mathrm{AOR}=6.17,95 \% \mathrm{CI}=2.55-14.96)$.

\subsubsection{Sex with a risky partner}

Women who had been arrested or incarcerated in the past 6 months were significantly more likely to have had a recent sex partner who was known or suspected to be HIV-positive or a recent injection drug user than women with no recent criminal justice involvement (unadjusted OR $=2.91$, 95\% $\mathrm{CI}=1.56-5.41)$. When adjusting for sociodemographic and other background characteristics, the estimate changed minimally $(\mathrm{AOR}=2.64,95 \% \mathrm{CI}=1.33-5.25)$. Adjustment for recent regular drug use resulted in a slightly weaker estimate that remained significant $(\mathrm{AOR}=2.54,95 \% \mathrm{CI}=$ 1.20-5.36). Regular injection drug use was strongly associated with having a risky sex partner $(\mathrm{AOR}=2.52$, $95 \% \mathrm{CI}=1.29-4.91)$. 
Table 3

ORs and 95\% CIs for the associations between arrest or incarceration in the past 6 months and high-risk sexual partnerships in the past 6 months among women aged 22 to 55 years enrolled in methadone maintenance treatment programs, New York City $(N=416)$

\begin{tabular}{|c|c|c|c|c|c|}
\hline \multirow[b]{2}{*}{$\begin{array}{l}\text { Arrest or incarceration } \\
\text { (past } 6 \text { months) }\end{array}$} & \multicolumn{5}{|c|}{ High-risk partnerships in the past 6 months } \\
\hline & $\begin{array}{l}\text { Number with high-risk } \\
\text { partnership }\end{array}$ & $\begin{array}{l}\text { Prevalence of high-risk } \\
\text { partnership (\%) }\end{array}$ & $\begin{array}{l}\text { Unadjusted OR } \\
(95 \% \mathrm{CI})\end{array}$ & $\begin{array}{l}\text { OR }(95 \% \mathrm{CI}) \text { adjusted } \\
\text { for respondent background } \\
\text { characteristics }^{\text {a }}\end{array}$ & $\begin{array}{l}\text { OR }(95 \% \mathrm{CI}) \text { adjusted for } \\
\text { background characteristics and } \\
\text { past 6-month regular drug use }\end{array}$ \\
\hline \multicolumn{6}{|l|}{ Multiple sex partnerships } \\
\hline No $(\mathrm{n}=370 ; 89 \%)$ & 40 & 11 & Referent & Referent & Referent \\
\hline Yes $(n=46 ; 11 \%)$ & 14 & 30 & $3.61(1.78-7.33)$ & $3.40(1.51-7.68)$ & $3.02(1.23-7.43)$ \\
\hline \multicolumn{6}{|l|}{ Sex trading } \\
\hline No & 34 & 9 & Referent & Referent & Referent \\
\hline Yes & 13 & 28 & $3.89(1.87-8.10)$ & $3.02(1.28-7.13)$ & $2.25(.86-5.88)$ \\
\hline \multicolumn{6}{|l|}{ Risky sex partner ${ }^{\mathrm{c}}$} \\
\hline No & 101 & 27 & Referent & Referent & Referent \\
\hline Yes & 24 & 52 & $2.91(1.56-5.41)$ & $2.64(1.33-5.25)$ & $2.54(1.20-5.36)$ \\
\hline \multicolumn{6}{|c|}{ High-risk partnership and unprotected sex ${ }^{\mathrm{d}}$} \\
\hline No & 92 & 25 & Referent & Referent & Referent \\
\hline Yes & 21 & 46 & $2.54(1.36-4.75)$ & $2.59(1.29-5.20)$ & $2.32(1.06-5.08)$ \\
\hline
\end{tabular}

${ }^{\text {a }}$ Background characteristics include race (Black, White, Hispanic, Asian/Other), age more than 40 years, high school diploma or equivalent, income (ordinal categorical), currently married, homeless in the past 6 months, employed in the past 6 months, years on methadone, current infection with HIV or another STI, psychological distress measured by BSI/Global Severity Index score, lifetime history of sexual abuse, and any same-sex partnerships in the past 6 months.

${ }^{\mathrm{b}}$ We adjusted for regular use (defined as using once or more per week) of each of the following in the past 6 months: heroin, stimulants (including amphetamine and powder cocaine), crack cocaine, marijuana, drugs without a prescription (including analgesics, tranquilizers, and sedatives), and any injection drug.

${ }^{\mathrm{c}}$ Risky sex partner is defined as a sex partner in the past 6 months who was known or suspected to be HIV-positive or a recent injection drug user.

${ }^{\mathrm{d}}$ In the past 6 months, participant has engaged in unprotected sex and at least one of the following: multiple sex partnerships, sex trading, or risky sex partner.

\subsubsection{High-risk partnership and unprotected sex}

In the unadjusted analyses, recent criminal justice involvement was associated with having both unprotected sex and at least one high-risk partnership (multiple sex partners, sex trading, and/or sex with a risky partner; OR = $2.54,95 \%$ CI $=1.36-4.75$ ). Adjusting for sociodemographic and background characteristics had little effect on the estimate, and in the fully adjusted model including recent regular drug use, the association remained strong and statistically significant (AOR $=2.32,95 \% \mathrm{CI}=1.06-5.08)$. Having both unprotected sex and a high-risk partnership was significantly associated with both regular crack cocaine use $(\mathrm{AOR}=2.22,95 \% \mathrm{CI}=1.08-4.54)$ and regular injection drug use $(\mathrm{AOR}=4.65,95 \% \mathrm{CI}=1.82-11.91)$.

\section{Discussion}

\subsection{Interpretation of findings}

This study highlights criminal justice involvement as a significant correlate of high-risk sexual partnerships in a sample of drug-involved women. The results are consistent with previous research that has linked a woman's incarceration to HIV infection (Altice et al., 2005; Maruschak, 2004; Rich et al., 1999). Unique aspects of this study are a focus on low-intensity criminal justice involvement (arrest or shortterm incarceration) and adjustment for regular drug use, social stressors, and psychological distress-HIV risk factors that disproportionately affect women offenders. Our two-stage adjusted analyses revealed that after controlling for sociodemographic and background characteristics, criminal justice involvement was strongly associated with each of the four sexual risk outcomes. Further adjustment demonstrated that regular drug use, particularly crack cocaine and injection drug use, is a major confounder to the association between criminal justice involvement and risky sexual partnerships. However, even after adjusting for regular drug use, three of the four high-risk sexual partnerships remained significantly associated with recent arrest or shortterm incarceration. Low-intensity criminal justice involvement may serve as a marker for HIV risk among druginvolved women due to the cyclical relationship between drug use, arrest, and incarceration. Moreover, the findings suggest the possibility that criminal justice involvement may have a unique impact upon sexual risk-taking beyond the role of drug use and other stressors.

Women in this study who were recently arrested or briefly incarcerated were more likely to engage in multiple sex partnerships. Although adjustment for sociodemographics and drug use attenuated this relationship, criminal justice involvement remained strongly associated with multiple sex partnerships in the fully adjusted model. The results are consistent with previously found associations between incarceration and multiple and concurrent partnerships among women (Khan, Wohl et al., 2008). These findings suggest that criminal justice involvement is associated with having multiple sex partners independent of adverse background factors and drug use, and one plausible explanation for this finding is that criminal justice 
involvement may increase the likelihood of HIV infection among drug-involved women by contributing to multiple sexual partnerships. Prior literature has suggested that the stress associated with criminal justice involvement, together with its disruptive effect on stable partnerships, may lead women offenders to engage in new and multiple partnerships (Adimora \& Schoenbach, 2005; Browning et al., 2001). The mounting evidence of the strong association between criminal justice involvement and multiple sex partnerships points to the need for research that can establish temporal sequencing to clarify the potential effect of involvement in the criminal justice system on women's relationships and health (Freudenberg, 2002).

Although criminal justice involvement was associated with sex trading in the unadjusted model, this relationship was not significant in the fully adjusted model, largely due to the confounding effects of regular crack cocaine use. This finding highlights the vulnerability of crack-using women to both HIV risk behaviors and repeated involvement with the criminal justice system (El-Bassel et al., 1996; Logan \& Leukefeld, 2000). The strong connection between drug use and criminal justice involvement also suggests that these two factors may work reciprocally and in tandem to lead to instability and sexual risk-taking, such as sex trading, among women.

Recent criminal justice involvement was highly correlated with having a risky sex partner. Past research on intimate partnerships has demonstrated a strong connection between personal and sexual partner incarceration and drug use (Epperson, Khan, El-Bassel, Wu, \& Gilbert, 2010). It is plausible, then, that drug-involved women who have recently been arrested or incarcerated are more likely to have sexual partners with direct and indirect risks associated with their own drug use. Moreover, even short-term criminal justice involvement may expose women to justice-involved sexual partners, who have high rates of HIV and injection drug use, thus increasing the overall risk of their sexual networks. Furthermore, the strong unadjusted and fully adjusted associations between criminal justice involvement and having both unprotected sex and a high-risk sex partnership warrant concern. Considering that $30 \%$ of the women in this study with recent criminal justice involvement report being HIV-positive, the association between criminal justice involvement and having both unprotected sex and a high-risk partnership indicates a significant opportunity for HIV transmission between drug-involved women offenders and their sexual partners.

\subsection{Study limitations}

There are several important limitations to this study. This study relies upon self-report data, without biological or case record confirmation of HIV status or criminal justice involvement. We were also unable to determine whether the study sample was significantly different from those who refused to participate, which may be a source of bias.
Although the sample's relative homogeneity on drug abuse is a unique strength for the study aims, the women in this study are, on average, somewhat older than the general population of women offenders, which may impact the generalizability of the findings. Further research is needed to ascertain whether criminal justice involvement is a unique indicator of HIV risk among diverse samples of women. The study uses a cross-sectional design and is therefore limited in its ability to draw a causal connection between the exposure of criminal justice involvement and HIV/STI risk. The findings provide evidence that criminal justice involvement is associated with high-risk sexual partnerships among drug-involved women. However, it is important to recognize that the relationship is likely embedded within a broader set of complex feedback relationships. That is, drug-involved women may engage in various high-risk behaviors, which could lead to increased likelihood of arrest or incarceration. In addition, engaging in some sexual risk behaviors, such as sex trading, is illegal and may place women at higher risk of arrest. Because this study did not ascertain reason for arrest, the association between illegal sexual risk behaviors and criminal justice involvement could not be tested. Longitudinal data that capture the temporal ordering of criminal involvement, drug use, sexual risk behaviors, and reason for arrest can help to uncover and clarify these relationships. Lastly, there is a time lag between collection of the data and dissemination of these findings; issues impacting this study may have changed over time, including support systems and HIV prevention efforts with drug-involved women offenders, and these changes could influence the multiple factors related to criminal justice involvement for women.

\subsection{Implications for HIV prevention}

Despite these limitations, the findings from this study offer several implications for HIV prevention. Druginvolved women with recent criminal justice involvement represent a group in great need of targeted HIV prevention services, and these women could be recruited from both drug treatment and criminal justice settings. Incarcerationbased HIV prevention efforts for women remain an important task. However, engaging women offenders outside of incarceration settings is difficult but necessary because more than $80 \%$ of the female correctional population is not presently incarcerated but situated in the community (i.e., on probation or parole) where they experience greater opportunities to engage in drug- and sexual-related risk behaviors (Belenko et al., 2004; Greenfield \& Snell, 1999; Spaulding et al., 2002). Probation and alternative to incarceration programs are potential settings to recruit such women for HIV prevention interventions (Belenko et al., 2004; Epperson et al., 2009). These strategies can build on existing HIV risk reduction efforts that focus primarily on incarcerated women to build a prevention continuum that more accurately reflects the breadth of the female criminal justice population. In 
addition, women in drug treatment programs, such as methadone treatment, who experience arrest or incarceration may face additional HIV risks and as such should be identified and targeted for involvement in HIV risk reduction programs.

Drug-involved women in the criminal justice system display a unique set of personal and social hardships. Mental health problems and drug abuse are highly prevalent among women offenders, and these stressors have been linked to sexual risk behaviors in previous research (Baillargeon et al., 2003; Logan \& Leukefeld, 2000; McCoy, Lai, Metsch, Messiah, \& Zhao, 2004). The overlapping risk factors of drug use, psychological distress, and criminal justice involvement present a complex challenge to addressing treatment and HIV prevention needs for drug-involved women (Peugh \& Belenko, 1999). Such interventions would benefit by including a psychosocial assessment and the capacity to link women to appropriate mental health services. An appraisal of service and support needs, such as housing and employment, may help to reduce not only HIV risk but criminal recidivism as well. In addition, considering the significant overlap between drug use and HIV risk for women offenders, access to drug treatment among offender populations must be expanded and understood as a potential protective factor against the spread of HIV (Semaan et al., 2002; Sorensen \& Copeland, 2000). Medical settings, particularly emergency departments, could include HIV screening, testing, and prevention efforts for women with drug involvement and overlapping risk factors. Particularly relevant to this study sample is the high risk of overdose after incarceration among opiate users, which should be addressed in prevention efforts with drug-involved women offenders (Binswanger et al., 2007; Wakeman, Bowman, McKenzie, Jeronimo, \& Rich, 2009).

\subsection{Conclusion}

This study finds that despite the considerable impact of drug abuse and other stressors on sexual HIV risk, criminal justice involvement remains a significant correlate of highrisk sexual partnerships among drug-involved women. An increased focus on the health risks and needs of druginvolved women in the criminal justice system is necessary to advance the health of this underserved population. Continued examination of criminal justice policy and practice as it affects women is therefore not only a matter of public safety but also an important component of public health.

\section{Acknowledgments}

The parent study was supported by the National Institute on Drug Abuse Grant R01DA011027 (PI Nabila ElBassel). Dr. Epperson's research is supported by a postdoctoral fellowship from the National Institute of Mental Health, Grant T32MH070313 (PI Nancy Wolff).
We wish to express appreciation to the women who chose to participate in this study.

\section{References}

Adimora, A. A., \& Schoenbach, V. (2005). Social context, sexual networks, and racial disparities in rates of sexually transmitted infections. Journal of Infectious Diseases, 191, S115-S122.

Altice, F. L., Marinovich, A., Khoshnood, K., Blankenship, K. M., Springer, S. A., \& Selwyn, P. A. (2005). Correlates of HIV infection among incarcerated women: Implications for improving detection of HIV infection. Journal of Urban Health, 82, 312-326.

Baillargeon, J., Ducate, S., Pulvino, J., Bradshaw, P., Murray, O., \& Olvera, R. (2003). The association of psychiatric disorders and HIV infection in the correctional setting. Annals of Epidemiology, 13, 606-612.

Belenko, S., Langley, C., Crimmins, S., \& Chaple, M. (2004). HIV risk behaviors, knowledge, and prevention education among offenders under community supervision: A hidden risk group. AIDS Education and Prevention, 16, 367-385.

Belenko, S., Lin, J., O’Connor, L., Sung, H., \& Lynch, K. (2005). Sexual and physical victimization as predictors of HIV risk among felony drug offenders. AIDS and Behavior, 9, 311-323.

Binswanger, I. A., Stern, M. F., Deyo, R. A., Heagerty, P. J., Cheadle, A., Elmore, J. G., et al. (2007). Release from prison-A high risk of death for former inmates. The New England journal of medicine, 356, 157.

Blank, M. B., \& Eisenberg, M. M. (2007). HIV and mental illness: Opportunities for prevention. Journal of Prevention \& Intervention in the Community, 33, 1-4.

Blankenship, K. M., Smoyer, A. B., Bray, S. J., \& Mattocks, K. (2005). Black-White disparities in HIV/AIDS: The role of drug policy and the corrections system. Journal of Health Care for the Poor and Underserved, 16, 140-156.

Browning, S., Miller, S., \& Lisa, M. (2001). Criminal incarceration dividing the ties that bind: Black men and their families. Journal of African American Men, 6, 87-102.

Castillo Mezzich, A., Tarter, R. E., Giancola, P. R., Lu, S., Kirisci, L., \& Parks, S. (1997). Substance use and risky sexual behavior in female adolescents. Drug Alcohol Depend, 44, 157-166.

CDC. (2008). HIV/AIDS surveillance report, 2006. Atlanta: U.S. Department of Health and Human Services, Centers for Disease Control and Prevention

Comfort, M., Grinstead, O., McCartney, K., Bourgois, P., \& Knight, K. (2005). "You can't do nothing in this damn place": Sex and intimacy among couples with an incarcerated male partner. The Journal of Sex Research, 42, 3-12.

Copersino, M., Meade, C., Bigelow, G., \& Brooner, R. (2010). Measurement of self-reported HIV risk behaviors in injection drug users: Comparison of standard versus timeline follow-back administration procedures. Journal of Substance Abuse Treatment, 38, 60-65.

Derogatis, L. (1993). Brief Symptom Inventory: Administration, scoring, and procedures manual. Minneapolis, MN: National Computer Systems, Inc.

El-Bassel, N., Gilbert, L., Krishnan, S., Schilling, R. F., Gaeta, T., Purpura, S., et al. (1998). Partner violence and sexual HIV-risk behaviors among women in an inner-city emergency department. Violence and Victims, 13, 377-393.

El-Bassel, N., Gilbert, L., Schilling, R. F., Ivanoff, A., Borne, D., \& Safyer, S. F. (1996). Correlates of crack abuse among drug-using incarcerated women: Psychological trauma, social support, and coping. American Journal of Drug and Alcohol Abuse, 22.

El-Bassel, N., Gilbert, L., Schilling, R. F., \& Wada, T. (2000). Drug abuse and partner violence among women in methadone treatment. Journal of Family Violence, 15, 209-225.

El-Bassel, N., Gilbert, L., Wu, E., Go, H., \& Hill, J. (2005). HIV and intimate partner violence among women on methadone. Social Science \& Medicine, 61, 171-183. 
El-Bassel, N., Ivanoff, A., Schilling, R. F., Borne, D., \& Gilbert, L. (1997). Skills-building and social support enhancement to reduce HIV risk among women in jail. Criminal Justice and Behavior, 24, 205-223.

El-Bassel, N., Ivanoff, A., Schilling, R. F., Gilbert, L., Borne, D., \& Chen, D. (1995). Preventing HIV/AIDS in drug-abusing incarcerated women through skills-building and social support enhancement: Preliminary outcomes. Social Work Research, 19, 131-141.

Epperson, M., Khan, M., El-Bassel, N., Wu, E., \& Gilbert, L. (2010). A longitudinal study of incarceration and HIV risk among methadone maintained men and their primary female partners. AIDS and Behavior.

Epperson, M., Platais, I., Valera, P., Barbieri, R., Gilbert, L., \& El-Bassel, N. (2009). Fear, trust, and negotiating safety: HIV risk contexts for Black women defendants. Affilia: Journal of Women and Social Work, 24, 257-271.

Freudenberg, N. (2002). Adverse effects of U.S. jail and prison policies on the health and well-being of women of color. American Journal of Public Health, 92, 1895-1899.

Frost, N. A., Greene, J., \& Pranis, K. (2006). Hard hit: The growth in the imprisonment of women, 1977-2004: Institute on Women \& Criminal Justice: Women's Prison Association.

Gilbert, L., El-Bassel, N., Rajah, V., Foleno, A., \& Frye, V. (2001). Linking drug related activities with experiences of partner violence: A focus group study of women in methadone treatment. Violence and Victims, 16, 517-536.

Greenfeld, L. A., \& Snell, T. (2000). Women offenders: US Department of Justice, Office of Justice Programs.

Greenfield, L. A., \& Snell, T. L. (1999). Women offenders. Bureau of Justice Statistics: Special Report, NCJ, 175688, 1-14.

Grella, C. E., Annon, J. J., \& Anglin, M. D. (2000). Drug use and risk for HIV among women arrestees in California. AIDS and Behavior, 4, 289-295.

Hammett, T. M., Harmon, M. P., \& Rhodes, W. (2002). The burden of infectious disease among inmates of and releasees from US correctional facilities, 1997. American Journal of Public Health, 92, 1789-1794.

Harlow, C. W. (1999). Prior abuse reported by inmates and probationers. Washington, DC: US Departnerment of Justice, Bureau of Justice Statistics.

Karberg, J. C., \& James, D. J. (2005). Substance dependence, abuse, and treatment of jail inmates, 2002. Bureau of Justice Statistics: Special Report, NCJ, 209588, 1-12.

Khan, M. R., Miller, W. C., Schoenbach, V. J., Weir, S. S., Kaufman, J. S., Wohl, D. A., et al. (2008). Timing and duration of incarceration and high-risk sexual partnerships among African Americans in North Carolina. Annals of Epidemiology, 18, 403-410.

Khan, M. R., Wohl, D. A., Weir, S. S., Adimora, A. A., Moseley, C., Norcott, K., et al. (2008). Incarceration and risky sexual partnerships in a southern US city. Journal of Urban Health: Bulletin of the New York Academy of Medicine, 85, 100-113.

Kim, A., Page-Shafer, K., Ruiz, J., Reyes, L., Delgado, V., Klausner, J., et al. (2002). Vulnerability to HIV among women formerly incarcerated and women with incarcerated sexual partners. AIDS and Behavior, 6, 331-338.

Logan, T. K., \& Leukefeld, C. (2000). Sexual and drug use behaviors among female crack users: A multi-site sample. Drug and Alcohol Dependence, $58,237-245$.

MacGowan, R., Margolis, A., Gaiter, J., Morrow, K., Zack, B., Askew, J., et al. (2003). Predictors of risky sex of young men after release from prison. International Journal of STD \& AIDS, 14, 519-523.

Marsch, L. A. (1998). The efficacy of methadone maintenance interventions in reducing illicit opiate use, HIV risk behavior and criminality: A metaanalysis.. Addiction, 93, 515-532.

Maruschak, L. M. (2004). HIV in prisons and jails, 2002. Bureau of Justice Statistics Bulletin, NCJ, 205333, 1-11.
Maruschak, L. M. (2005). HIV in prisons, 2003: U.S. Department of justice: Office of Justice Programs.

Mauer, M., \& Kins, R. S. (2007). A 25-year quagmire: The war on drugs and its impact on American society. Washington, DC: The Sentencing Project.

Mays, D., Gordon, A., Kelly, M., \& Forman, S. (2005). Violent criminal behavior and perspectives on treatment of criminality in opiate treatment. Substance Abuse, 26, 33-42.

McCoy, C. B., Lai, S., Metsch, L. R., Messiah, S. E., \& Zhao, W. (2004). Injection drug use and crack cocaine smoking: Independent and dual risk behaviors for HIV infection. Annals of Epidemiology, 14, 535-542.

Mullings, J., Marquart, J., Carr, T., \& Hartley, D. (2004). Knowledge is not always power: HIV risk behavior and the perception of risk among women prisoners. Journal of Correctional Health Care, 11, 59-78.

NYCDOH. (1999). HIV seroprevalence update. New York: New York City Department of Health - AIDS Research/ HIV Serosurvey Program.

Peugh, J., \& Belenko, S. (1999). Substance-involved women inmates: Challenges to providing effective treatment. The Prison Journal, 79, 23.

Pew. (2009). One in 31: The long reach of American corrections. Washington, DC: The Pew Charitable Trusts.

Rich, J. D., Dickinson, B. P., Macalino, G., Flanigan, T. P., Towe, C. W., Spaulding, A., et al. (1999). Prevalence and incidence of HIV among incarcerated and reincarcerated women in Rhode Island. Joural of Acquired Immune Deficiency Syndromes, 22, 161.

Rindfuss, R., \& Stephen, E. H. (1990). Marital noncohabitation: Separation does not make the heart grow fonder. Journal of Marriage and the Family, 52, 259-270.

Semaan, S., DesJarlais, D., Sogolow, E., Johnson, W., Hedges, L., Ramirez, G., et al. (2002). A meta-analysis of the effect of HIV prevention interventions on the sex behaviors of drug users in the United States. Journal of Acquired Immune Deficiency Syndromes, 30(Supplement 1), S73-S93.

Sgroi, S. (1982). Handbook of clinical intervention in child sexual abuse. Lexington, MA: D.C. Heath and Company.

Somlai, A., Kelly, J., Wagstaff, D., \& Whitson, D. (1998). Patterns, predictors, and situational contexts of HIV risk behaviors among homeless men and women. Social Work, 43, 7-20.

Sorensen, J. L., \& Copeland, A. L. (2000). Drug abuse treatment as an HIV prevention strategy: A review. Drug and Alcohol Dependence, 59, $17-31$.

Spaulding, A., Stephenson, B., Mecalino, G., Ruby, W., Clarke, J. G., \& Flanigan, T. P. (2002). Human immunodeficiency virus in correctional facilities: A review. HIV/AIDS, 35, 305-312.

Staton-Tindall, M., Leukefeld, C., Palmer, J., Oser, C., Kaplan, A., Krietemeyer, J., et al. (2007). Relationships and HIV risk among incarcerated women. The Prison Journal, 87, 143-165.

Sterk, C. E. (1999). Fast lives: Women who use crack cocaine. Philadelphia, PA: Temple University Press.

Sterk, C. E. (2002). The health intervention project: HIV risk reduction among African American women drug users. Public Health Reports, 117, S88-S95.

Wakeman, S., Bowman, S., McKenzie, M., Jeronimo, A., \& Rich, J. (2009). Preventing death among the recently incarcerated: An argument for Naloxone prescription before release. Journal of Addictive Diseases, 28, 124-129.

Wheelock, D., \& Uggen, C. (2005). Race, poverty and punishment: The impact of criminal sanctions on racial, ethnic, and socioeconomic inequality (pp. 15-16). Ann Arbor: National Poverty Center at the University of Michigan.

Wu, E., El-Bassel, N., Gilbert, L., \& Morse, P. (2006). Dyadic HIV status and psychological distress among women on methadone. Women's Health Issues, 16, 113-121. 